\title{
A study of experiential learning features in two departments at Haifa University International School: Jewish Studies and Israel Studies
}

\author{
Dr. Gabriel Mayer
}

\begin{abstract}
This study examines the student cohorts of the Haifa University International School departments of Jewish Studies and Israel Studies. Specifically addressed will be subject content that is not directly named or expressed within the curricula of courses offered, but nonetheless constitutes approximately $25 \%-30 \%$ of student course time. These are experientially guided encounters dispersed throughout the multiple courses offered, but while unique, this aspect of learning has hitherto remained unidentified, not quantitated, nor in any manner recognized as a significant teaching and learning experience. Underlying the students' encounter with these programs are issues of culture and identity. One way of saying this would be, the study of a moment when Jewish [Israel] peoplehood meets a transnational peoplehood. One of the basic elements guiding the study is the long held belief and conviction that Israel is the land of the Jews from Biblical times onward. Thus the visiting of many sites, monuments, landmarks and even settlements-old and new-is a uniquely different experience from similar activities in other programs and other countries. Here in these study programs which are all within the scope of the discipline of history, the students gain a palpable encounter with their subject matter and during their stay in Israel they are experiencing an annual cycle of holidays and festivals that conform to biblical history as well as the nation building narrative of their host land.
\end{abstract}

\section{INTRODUCTION}

Two departments in the Haifa University International School-the Jewish Studies and Israel Studies-are uniquely intertwined in course contents and general curricula. The courses offered in each department may be taken as electives in the alternative department. While there are a group of core subjects uniquely necessary to graduate either program, in essence, all of the courses are included in the pool of electives that may be chosen. The student cohorts are quite similar for both programs and are typified as a group of students from a wide international background as well as local Israeli students. This fact presents a unique opportunity to study a relatively large group of students each year who remain homogeneous from year to year of program study. ${ }^{1}$

The large number and variety of field trips present a most unique aspect of these programs. Along with some department wide organized cultural experiences it is estimated that upward of $25 \%$ of student class time is spent not in a classroom but visiting important sites and relevant locations. Many are course content specific, but as an aggregate they are a remarkable collection of experiential encounters. While experiential teaching in traditional subject matters as well as organized group experiences arrayed along the theme of peoplehood and identity are ubiquitous on many campuses as well as independent institutions, this particular aspect of the learning/teaching experience at Haifa University has never been formally recognized nor

${ }^{1}$ (Krauss 2005, Langman 1999) Excellent references that guide the general principles this study undertakes. 
addressed in any meaningful manner. Indeed, interviewing the department chairs resulted in a surprised reaction and was a cause of befuddlement.

\section{Significance of the Research}

I initially described this to a faculty member as a story. Imagine, I stated, that one day the elevator in the main building suddenly stopped at a previously unknown floor, the rear door opened and I walked into a brand new, fully equipped and never used laboratory. One main significance of the proposed study lies in that perhaps this is the first time any of the curricula at the International School are being examined from a non-traditional viewpoint. The practice of experiential teaching and non-traditional curricula are well known in academia and thoroughly documented in the literature. ${ }^{2}$ The fact that we are utilizing such methods at the International School goes largely unobserved. However, there is much more to be gained from such a proposed investigation, well beyond the novelty concept. When exposing a group of international students-understanding the same while there are a number of Israeli students present-to personalized experiences with their surroundings, the host country, and, for the most time, the true and original location of the subject matter in most courses, a relationship develops far beyond the normal concepts of acceptable knowledge base. ${ }^{3}$ While in educational academia this is most often labeled experiential learning, a more sophisticated reference point would borrow from linguistics philosophy and put in use J.L Austen's principles of performativity. Under these principles, the parameters and boundaries of what is considered as a learning moment or exposure are greatly augmented by the multiple characteristics of the event. ${ }^{4}$ As an example, consider a field trip to a monument. Initially, the visit with all the accompanying textbook knowledge of history and social statistics appears to offer a large amount of content material. Yet overlooked are all the other components, starting with organizing of the trip, continuing with the very act of the trip across historically and socially important landscape while continually immersed in interpersonal dialogue with faculty and other students.

While the methodology to be utilized will be detailed subsequently, I would like to make note of the fact that adapting and using methodologies for this study will be in of itself a great contribution. Finally, in order to provide a better picture of the sort of activities those go into creating a performativity driven learning opportunity, I wish to provide a vignette into one of the courses taught. Professor Oz Almog teaches a course named Modern Israeli Society and the course consists entirely of field trips. One of these trips is dedicated to viewing the Druse society; the Druse are a very important Arab minority with significant links to economic and military aspects of Israel society. ${ }^{5}$ Prior to the trip and visits, the students are provided with an extensive background or facts sheet which detail historical and socioeconomically important data. During the trip, each site visited affords the opportunity to interact with representatives of the communities. What makes these encounters really stand out and effective is the fact that during the beginning of each academic year, the students of both departments are invited to an evening out to a Druse community and restaurant. All the students, as well as some past students, and the faculty members of both departments typically attend this event. When stepping back and looking at the combination effect and resulting vision the students have received, we point to an almost palpable learning experience. Indeed, I would state, that the

\footnotetext{
2 (Romi and Lev 2007, Sasson et al. 2008, Saxe and Boxer 2012, Saxe, Sasson, and Hecht 2006) The basic principles of studying student centered and experientially bound academic work are well documented in the literature.

3 (Soifer 1991)

4 (Austin 1975) A landmark work that precipitated a watershed moment in linguistic philosophy and propagated its applicability in many disciplines.

${ }^{5}$ (Almog 2004) A best selling work that also gave way to serious academic reconsiderations.
} 
students who partake in the combination of the aforementioned events will come away with a better understanding of the Druse and their relationship to Israeli society in general, than most native and locally schooled Israeli citizens. ${ }^{6}$

\section{Study Design}

Developing this proposal was a "mini" research study by its very nature. A number of faculty members were consulted and interviewed in order to generate ideas for what will be in the end a project with a "looking at us" characteristic. In describing the evolution of the proper methodology, I hope to shed some insight into the delicate confines of academic discipline "border zones" necessitated by working in the educational curricula milieu, while emphasizing and studying subject matters of history and seeking, in the end, an output defined by notions of identity. Beginning with Dr. Micha Perry, the head of the Jewish Studies department, I asked if anyone has formally, or even casually, looked at the non-classroom curricula or what would be called such. Dr. Perry suggested that I speak with Professor Hanan Alexander whose specialty is in the field of education and curricula designs. He was quick to point out that the main thrust or "playing field "of this project was in the discipline of education, which by his accord is vast and varied, yet for my purposes confined to a very narrow scope of researchers. Progressing from this framework I was led to Professor Zvi Bekerman of Oranin College. Specializing in the anthropology of education and having achieved much recognition in the studies of identity and culture he embraced the scope of the study and urged me to chose a suitable methodology. This proved to be a dicey proposition. Much of his work and examples of similar studies in the literature rely on a constructivist approach as regards epistemology. In other terms this is termed qualitative research and studies are designed for observational evaluation and may be said to rely on subjective evaluation. For my purposes this was not ideally suited for two reasons. One is the time element, since the cohorts I intend to study are on site (campus) typically for a time period that lasts a year or less, and in this case it becomes a "moving target" situation when it comes to data gathering. Furthermore the qualifying and credibility of a qualitative observer may be stretching the limitations of my abilities. Nonetheless, researching the capacities inherent in such an approach did shed light on what I ultimately have decided to utilize. For my purposes, I wish to employ straightforward positivistic data gathering. Under this scenario I can set definitive time periods for a study, tailor make follow-up and continuity, and finally have access to irrefutable measuring tools that rely on statistics and hard data. ${ }^{7}$

Thus while abandoning the study designs most commonly employed by Professor Bekerman and similar researchers, I will make use of the knowledge base utilized in their studies of peoplehood and identity. ${ }^{8}$

\section{Existing Academic Work to Reflect the Study}

The Cohen Center at Brandeis University has long sponsored seminars, coursework, and research aimed at identifying and evaluating traditional and non-traditional curricula that address Jewish peoplehood. A key element that has been followed is the tension between a narrated curriculum and the top-bottom approaches versus the user-generated discovery of students inserted in-situ the culture and country [Israel]. The best-known and most voluminous work has been with groups of Taglit student visitors to Israel. ${ }^{9}$ Besides the vast amount of information obtained, some of which will be addressed later, the center has also

\footnotetext{
${ }^{6}$ (Yemini, Bar-Nissan, and Yardeni 2014, Zembylas and Bekerman 2008) Site bound historical relativity has been previously examined by a variety of academics.

7 (Silverman 2015); (Krauss 2005); (Alexander 2005, 2006)

8 (Alexander 1986); (Bekerman and Maoz 2005); (Yakobson 2008)

9 (Sasson et al. 2008, Saxe and Boxer 2012, Saxe, Sasson, and Hecht 2006)
} 
developed sets of questionnaires for data analysis. Basically, there is a repository of study questions and well-designed investigative technology from which it would be easy to adapt material germane to my own work. These studies take aim at some of the desirable research questions I hope to raise, and are an easy template from which to derive and adopt tools for my own research.

\section{Construction of work}

Having established a general conceptual background, the following lays out a range of proposed topics that are under consideration. At this early starting point, there are variables, which will only manifest as the work progresses.

\section{The general setting:}

The International School and MA programs in Israel Studies and Jewish Studies are highlighted as noteworthy for study because of the multi ethnographic composition of cohorts and the fact that while greatly varied, the variations form year to year are quite similar. If this statement holds out statistically then the prospective studies will yield respectable numbers to work with.

\section{Unique Curricula}

The curricula and courses will yield a detailed analysis of the range of courses being discussed and we will analyze syllabi for described and desirable content. Further considerations depend on the extracurricular activities or sites and visits: In this manner, I introduce the concept of non-classroom learning and user generated outcomes. At this point the major concepts are discussed while some details emphasized later delve much deeper into research and literature. Besides studying the students' reaction and experience, it will become noteworthy to examine the academic staff and their understanding of the process.

\section{What is user-generated learning?}

Essentials of experiential learning exposure are dependent on concepts of user generated learning and the notion of performativity evinced through the Israeli experience, be it geography, historiography, archeology, or even culinary and theatrical. ${ }^{10}$ The significance of this is magnified as relates to world opinion and foreign relations. While small in numbers, the foreign students come from a relatively elite portion of their countries' population. Thus, upon returning home, the experience gained in Israel will become a magnified projection and may have profound long-term effects on Israel's international relations. Let's just say, it is always good PR. Culture and identity are inexorably linked in academic literature as well as in practical matters; until now, similar teaching/learning methods have been funded and supported typically by Jewish groups and have centered on the notion of Jewish Peoplehood. However, in many cases, and exactly like the one we have here, the circumstances present an intersection of varied peoplehood.

\section{Best Practices as Relating to Quantitative Research}

Specifics of the study design determine the here and how and are fundamentally inherent in developing the exact study design, i.e. the tools of measurement. Various questionnaires are to be presented and the nature of questions, the frequency of administration, as well as time intervals are all discussed and justified. The legality and appropriateness of administering study questions will need to channel through appropriate university administrative resources.

10 (Langman 1999, Mittelberg 2011, Ram 1995, Raviv 2016, Romi and Lev 2007, Sasson et al. 2008) 
Further details of the study design are to be discovered as practical means of implementation are negotiated with administrative authorities.

\section{What is the importance of my work?}

This, to be discussed at length upon conclusion of the study, will reconfirm the ideas, which have prompted this inquiry. One principle to be focused on is the presence of a layer of education embedded in the study programs of the Jewish Studies and Israel Studies that has never been formally identified, nor discussed, and never evaluated. It has been a hidden agenda, a sort of secret treasure. In embarking to study and analyze the phenomena of experiential learning as conveyed by the performative features of events occurring within certain classes as well around the program-these would be the dual departmental organized events-we are presented with rich layers of experience. Whenever the students are experiencing these events, there is a mixing of identity and this is where cultures truly meet on a personal level. These experiences profoundly affect learning and the body of knowledge the students gain during the program and may be the most important features carried forward in the future when students return to their country of origin. Here the possibilities for PR and foreign relations cannot be overstated. The key to the most important elements of this study is to examine the notions of identity and culture within a multicultural cohort.

\section{References:}

Alexander, Hanan A. 1986. "Cognitive relativism in evaluation." Evaluation Review 10 (http://www.gfh.org.il/Eng/?CategoryID=232):259-280.

Alexander, Hanan A. 2005. "Human agency and the curriculum." School Field 3 (http://www.gfh.org.il/Eng/?CategoryID=232):343-369.

Alexander, Hanan A. 2006. "A view from somewhere: Explaining the paradigms of educational research." Journal of philosophy of education 40 (http://www.gfh.org.il/Eng/?CategoryID=232):205-221.

Austin, John Langshaw. 1975. How To Do Things With Words. Edited by Urmson and Sbisa. Cambridge, Massachusets: Harvard University Press.

Barzilai, Gad. 2010. "'Who Is a Jew?'Categories, Boundaries, Communities and Citizenship Law in Israel." Boundaries of Jewish Identity:27-42.

Bekerman, Zvi. 2009. "Identity versus peace: Identity wins." Harvard Educational Review 79 (1):74-83.

Bekerman, Zvi. 2009. "Identity versus peace: Identity wins." Harvard Educational Review 79 (1):74-83.

Bekerman, Zvi, and Ifat Maoz. 2005. "Troubles with identity: Obstacles to coexistence education in conflict ridden societies." Identity 5 (Vashem):341-357.

Crichlow, Warren. 2013. Race, identity, and representation in education: Routledge.

DellaPergola, Sergio. 2014. "Jewish Peoplehood: Hard, Soft, and Interactive Markers." Reconsidering IsraelDiaspora Relations. Leiden y Boston, Brill:25-59.

Erickson, Frederick. 1985. "Qualitative Methods in Research on Teaching. Occasional Paper No. 81."

Gitelman, Zvi. 1998. "The decline of the diaspora Jewish Nation: Boundaries, content, and Jewish identity." Jewish Social Studies 4 (http://www.gfh.org.il/Eng/?CategoryID=232):112-132.

Kilbourn, Brent. 2006. "The qualitative doctoral dissertation proposal." Teachers College Record 108 (Vashem):529.

Kopelowitz, Ezra, and A Engelberg. 2007. "A framework for strategic thinking about Jewish peoplehood." Position Paper Commissioned by the Nadav Fund.

Kopelowitz, Ezra, and Ari Engelberg. 2007. "JEWISH PEOPLEHOOD."

Krauss, Steven Eric. 2005. "Research paradigms and meaning making: A primer." The qualitative report 10 (Vashem):758-770.

Langman, Peter F. 1999. Jewish issues in multiculturalism: A handbook for educators and clinicians: Jason Aronson Incorporated. 
Mittelberg, David. 2011. "Jewish peoplehood education." In International handbook of Jewish education, 515-539. Springer.

Ram, Uri. 1995. "Zionist historiography and the invention of modern Jewish nationhood: The case of Ben Zion Dinur." History and memory 7 (1):91-124.

Raviv, Zohar. 2016. "A Fresh View of "Let My People Go..." ". https://www.brandeis.edu/hornstein/topics-inleadership/Zohar-Raviv_Jewish-Peoplehood.html.

Romi, Shlomo, and Michal Lev. 2007. "Experiential learning of history through youth journeys to Poland: Israeli Jewish youth and the Holocaust." Research in Education 78 (1):88-102.

Sasson, Theodore, David Mittelberg, Shahar Hecht, and Leonard Saxe. 2008. "Encountering the other, finding oneself: The Taglit-Birthright Israel mifgash." Taglit-Birthright Israel.

Saxe, Leonard, and Matthew Boxer. 2012. "Loyalty and love of Israel by diasporan Jews." Israel Studies 17 (http://www.gfh.org.il/Eng/?CategorylD=232):92-101.

Saxe, Leonard, Theodore Sasson, and Shahar Hecht. 2006. "Taglit-Birthright Israel: Impact on Jewish identity, peoplehood, and connection to Israel." Taglit-Birthright Israel.

Silverman, David. 2015. Interpreting qualitative data: Sage.

Soifer, Steven. 1991. "Infusing content about Jews and about anti-semitism into the curricula." Journal of Social Work Education 27 (http://www.gfh.org.il/Eng/?CategoryID=232):156-167.

Yakobson, Alexander. 2008. "Jewish Peoplehood and the Jewish State, How Unique?:-A Comparative Survey." israel studies 13 (http://www.gfh.org.il/Eng/?CategorylD=232):1-27.

Yemini, Miri, Hed Bar-Nissan, and Oriah Yardeni. 2014. "Between "us" and "them": Teachers' perceptions of the national versus international composition of the Israeli history curriculum." Teaching and Teacher Education 42:11-22.

Zembylas, Michalinos, and Zvi Bekerman. 2008. "Education and the dangerous memories of historical trauma: Narratives of pain, narratives of hope." Curriculum Inquiry 38

(http://www.gfh.org.il/Eng/?CategorylD=232):125-154. 